\title{
Spatial frequency processing and the prediction of reading ability: A preliminary investigation
}

\author{
WILLIAM LOVEGROVE, WALTER SLAGHUIS, ALISON BOWLING, \\ PETER NELSON, and ESTELLE GEEVES \\ University of Tasmania, Hobart, Tasmania
}

\begin{abstract}
Measures of vocabulary, digit span, and pattern-contrast sensitivity for low- to medium-spatialfrequency gratings were collected from 123 representative prereaders. A multiple regression analysis showed that these were moderate predictors of reading ability 2 years later. The contrastsensitivity measure made a significant unique contribution to the regression equation. The results are interpreted in terms of recent data that indicate a transient-system deficit in specifically disabled readers.
\end{abstract}

A substantial body of evidence supports the view that specific reading disability is not linked in any systematic way to visual deficits (Benton, 1962, 1975; Manis \& Morrison, 1982; Vellutino, 1979). A potential problem with much of the earlier work on this topic is the absence of an appropriate theoretical framework for such research. Contemporary vision research has provided a framework (see Campbell, 1974, for a review) in the form of spatialfrequency analysis. Furthermore, the application of this framework to an analysis of the basic visual mechanisms involved in reading has received considerable attention (Breitmeyer, 1980, 1983; Breitmeyer \& Ganz, 1976).

This approach is based on the evidence for a number of parallel channels within the visual system, each of which processes a particular type of spatial information (Blakemore \& Campbell, 1969). Each channel responds optimally to a narrow range of stimulus orientations and widths. The stimulus most commonly used in such experiments is a repetitive pattern of black and white bars. The luminance pattern across these bars forms a sine wave and the patterns are referred to as sine-wave gratings. Their width or size is specified in terms of spatial frequency or number of cycles (one black plus one white bar) per degree of visual angle (cpd).

There is substantial evidence that these spatial channels also have different temporal properties. The general finding is that low spatial frequencies are processed more quickly than are high spatial frequencies when measured by reaction time (Breitmeyer, 1975; Vassilev \& Mitov, 1976), visible persistence duration (Bowling, Lovegrove, \& Mapperson, 1979; Meyer \& Maguire, 1977), duration of temporal integration (Breitmeyer \& Ganz, 1977; Legge, 1978), or subthreshold summation (Watson \& Nachmias, 1977). Although it can be argued that visible

The authors gratefully acknowledge the assistance of the Research Branch of the Tasmanian Education Department and the children tested. This research was supported by a grant from the Australian Research Grants Scheme to W. J. Lovegrove, whose address is now Department of Psychology, University of Wollongong, P.O. Box 1144, Wollongong, New South Wales 2500, Australia. persistence may not be a measure of processing duration, this is less likely to be the case with the other measures used. The similar effect of spatial frequency on all of these measures suggests that they may all reflect aspects of temporal resolution.

This possibility has led to proposals that there are two subsystems within the visual system (Keesey, 1972; Kulikowski \& Tolhurst, 1973; van Nes, Koenderick, Nas, \& Bouman, 1967). The transient system is essentially a low-spatial- and high-temporal-frequency system. The sustained system, on the other hand, is primarily a highspatial- and low-temporal-frequency system. Although there has been some debate about the independence and functions of these systems (Derrington \& Henning, 1981; Lennie, 1980), recent evidence strongly supports their existence (Burbeck \& Kelly, 1981; Green, 1984; Pantle, 1983; Regan \& Neima, 1984).

In this laboratory, extensive research on specific reading disability has been conducted within this framework. Some of this work has measured duration of visible persistence (a suprathreshold measure of temporal processing) across spatial frequencies (Badcock \& Lovegrove, 1981; Lovegrove, Heddle, \& Slaghuis, 1980; Slaghuis \& Lovegrove, 1984, 1985). Other work has investigated pattern-contrast sensitivity as a function of spatial frequency (Lovegrove, Bowling, Badcock, \& Blackwood, 1980; Lovegrove et al., 1982; Martin \& Lovegrove, 1984). A third series of experiments has investigated sensitivity to flicker across different spatial and temporal frequencies (Martin \& Lovegrove, in press).

The results from these experiments are consistent. They show that, on each measure, specific-reading-disabled subjects (SRDs) and controls have different patterns of sensitivity across spatial frequencies. On the persistence measures, SRDs show little change across spatial frequencies compared to that shown by controls. On measures of pattern-contrast sensitivity, they are less sensitive than are controls at low spatial frequencies, but more sensitive at high spatial frequencies. The temporal sensitivity experiments show that SRDs are less sensitive than con- 
trols at all temporal frequencies, but the difference increases with increasing flicker rate. It has been argued in detail elsewhere (Lovegrove, Martin, \& Slaghuis, 1986) that all of these results are consistent with a transientsystem deficit in SRDs.

An analysis of data for individual subjects is of considerable interest. On measures of the regression coefficient of the function relating visible persistence duration to spatial frequency, a discriminant analysis showed that $80 \%$ of SRDs differ from controls (Slaghuis \& Lovegrove, 1985). A comparison of individual subjects on the flicker data shows that there is almost no overlap at all between SRDs and control subjects (Martin \& Lovegrove, in press). The pattern-contrast sensitivity measures, however, although they show significant group differences, are less accurate in discriminating between individual subjects from the two groups.

In summary, the data from this laboratory (based on approximately 150 disabled and 150 control readers) support the notion of a transient-system deficit in SRDs. Furthermore, such a deficit appears to be present in at least $80 \%$ of SRDs tested. These conclusions contrast strongly with two prevailing views in the literature. The first is that SRDs generally do not demonstrate any systematic visual deficit. The second is that there are subgroups of SRDs (Boder, 1973; Doehring \& Hoshko, 1977; Mattis, French, \& Rapin, 1975; Satz \& Morris, 1981), only a few of which have any visual deficit.

Lovegrove, Martin, Hart, and Cuthbert (1986) investigated sustained-system processing in SRDs and controls by measuring orientation and spatial-frequency tuning. These experiments failed to show any differences in spatial tuning between SRDs and controls. Lovegrove et al. concluded that SRDs differ from controls in the functioning of their transient, but not their sustained, systems.

What is not yet known is how or even whether a transient-system deficit contributes to a reading problem. It is, for example, possible that such differences between SRDs and controls arise because one group learns to read and the other does not. If it were possible to demonstrate that measures of contrast sensitivity before learning to read predict reading ability some time later, it could be concluded that the observed visual processing differences do not arise from one group's failure to learn to read.

Previous research has shown little evidence that measures of visual processing predict later reading ability. Some studies have indicated a higher level visual processing contribution to subsequent reading achievement. These studies, however, have shown only correlational scores (Clark, Bruinink, \& Glaman, 1978; Warren, Widawski, \& Anooshian, 1976). Studies that have gone on to carry out regression analyses with these variables have shown that visual tasks add little to the predictive value, and have not included these tasks in the final regression equation (Satz \& Friel, 1974).

Other studies have shown low correlations between visual tasks or visual training administered in kindergarten and later reading achievement (McNinch, 1974; Wil- liams \& Brekke, 1977). A study by Warren, Anooshian, and Widawski (1975), using several tests of visualauditory integration, found significant correlations with later reading ability. A regression analysis found that several of these integrative abilities were correlated with reading independently of the other measures, but only for children in Grade 1. It is speculated that previous studies failed to find a predictive relationship between measures of visual processing and later reading ability because they measured sustained- rather than transient-system processing.

The present paper reports data on the relationship between contrast sensitivity for low-spatial-frequency gratings in children aged 6 years and reading ability at age 8 years. Prereading scores on a vocabulary test and an auditory-sequencing or digit-span test were also correlated with reading ability 2 years later.

\section{METHOD}

\section{Subjects}

Initially, 201 subjects were tested on measures of contrast sensitivity, vocabulary, and digit span. These were all of the kindergarten children at seven Hobart schools chosen as representative of a reasonable socioeconomic cross-section. In the total sample, males and females were approximately equally represented. Because of transfers to other schools and because of absences from school, only 123 of the original children were available at the time of follow-up testing. Their mean age at the time of original testing had been 5 years, 11 months. Their mean age at the time of follow-up testing was 8 years, 3 months, as shown in Column 1 of Table 2.

\section{Procedure and Apparatus}

Contrast sensitivity measurement. The stimuli were photographic prints of sine-wave gratings with spatial frequencies of 2 and $4 \mathrm{cpd}$. These spatial frequencies were chosen because previous research (Lovegrove, Bowling, et al., 1980; Lovegrove et al., 1982; Martin \& Lovegrove, 1984) had shown SRDs to be less sensitive than controls at these values. Furthermore, the results of Breitmeyer, Levi, and Harwerth (1981) showed some transient involvement in the detection of stationary gratings at these spatial frequencies. The gratings were presented in a Scientific Prototype tachistoscope (Model GB) through a circular field with a $3.5^{\circ}$ diameter. The grating stimulus was placed in Field 1 of the tachistoscope and blank cards were positioned in Fields 2 and 3.

A polarizing filter was positioned at the viewing end of the tachistoscope and mounted so that it could be easily rotated. Rotation of this filter through $90^{\circ}$ caused the combined stimulus from Fields 1 and 2 to change from a clear blank field (or at least very close to a blank field) at $0^{\circ}$ to a high-contrast grating at $90^{\circ}$. The luminances of Fields 1 and 2 were each adjusted to $1.5 \mathrm{~cd} / \mathrm{m}^{2}$ with the rotating polarizing filter at $0^{\circ}$ and $90^{\circ}$, respectively. Rotation of the polarizing filter consequently changed the contrast of the stimulus without changing its space-average luminance. A neutral density filter was placed in Field 3 of the tachistoscope and Field 3 's luminance was adjusted to $1.5 \mathrm{~cd} / \mathrm{m}^{2}$. This field provided the background against which the adjustable contrast stimulus was presented; it was illuminated continuously except during stimulus presentation. The small size of the rotating polarizing filter necessitated monocular presentation throughout the experiment.

The subjects were familiarized with the testing equipment and procedure. Thresholds were then determined for gratings of 2 and 4 cpd exposed for $350 \mathrm{msec}$. On half the trials in a condition, a vertical grating was used, and on the remainder a blank of the same 
space-average luminance was used. The subject was required to say whether or not the target grating was present. Detection was measured by a blockwise tracking method. In each condition the teststimulus contrast was varied in steps of .001 between blocks of 12 trials ( 6 gratings and 6 blank presentations, in random order) until the subject achieved $75 \%$ accuracy in a single block or bracketed this value between successive blocks. Both ascending and descending trials were used. Half the subjects had the 2-cpd grating first, and the remainder had the 4-cpd grating first. Viewing was monocular and each subject used his/her preferred eye. Testing took approximately 10 min per subject.

Vocabulary assessment. This was done by a teacher especially employed for the task. The test used was the Vocabulary Test of the Tasmanian Early Assessment Programme (1977). This test consists of the following words: hat, loop, dress, damp, near, unhappy, tomato, rest, patch, afraid, cruel, and blaze. Each child was tested individually and was asked to explain the meaning of each word in turn; replies were immediately scored on the record form. The child was asked, for example, "What is a hat?" "What is a hat like?" "What do you do with a hat?" or "Tell me what a hat is." If necessary, the word to be defined was used in this way three or four times, without indicating its meaning. A score of 1 was given for a correct answer and 0 for an incorrect answer. The possible range of scores was from 0 to 12 .

Digit-span assessment. This was administered by the teacher who administered the vocabulary test. It is a standard digit-span test and comes from the Tasmanian Early Assessment Programme (1977). Sequences from two to six digits were used. Only forward recall was tested. Each sequence could be presented a second time if the first trial was a failure. A score of 2 was given if the child was correct on the first trial, 1 if correct on the second trial, and 0 if incorrect on the second trial. A total of 13 sequences was used, giving a maximum score of 26 . Equal scores were given to all correct sequences, regardless of length.

Reading assessment test. Approximately 2 years after the initial testing, a tester who had not been involved in any of the previous testing administered the Neale Analysis of Reading Ability (1966) to each child individually.

\section{RESULTS}

\section{Contrast Sensitivity Measures}

The threshold for detection under each condition was taken as the contrast required for $75 \%$ differentiation of the target from the blank trials. For each subject the orientation of the rotating polarizing filter was converted to a relative contrast value by the formula contrast $=\sin ^{2} \sigma$. The log contrast threshold scores were then converted to $\log$ sensitivity scores where $\log$ sensitivity $=1 /$ contrast threshold. The mean value for 2- and 4-cpd gratings was found and this combined score was used as a measure of low-spatial-frequency sensitivity.

The mean combined log contrast sensitivity scores are shown in Column 4 of Table 1.

Table I

Mean Age, Vocabulary, Digit Span, and Contrast Sensitivity Scores at Time of Initial Testing $(N=123)$

\begin{tabular}{lrcccc}
\hline & & & \multicolumn{3}{c}{ Log Contrast } \\
\hline & Age & Vocabulary & Digit Span & Sensitivity* \\
\hline Mean & 5 years 11 months & 10.2 & 20.8 & 1.29 \\
Variance & .24 months & 1.1 & .36 & .01 \\
\hline
\end{tabular}

*Average 2 and $4 \mathrm{cpd}$.
Table 2

Mean Age, Mean Neale Analysis of Reading Ability (NARA) Scones, and Mean Chronological Age/Reading Age (CA/RA) Discrepancy Score at Time of Second Testing

\begin{tabular}{lccc}
\hline & Age & NARA & CA/RA \\
\hline Mean & 8 years 3 months & 8 years 10.4 months & 7.4 months \\
Variance & 2.4 months & 9.6 months & 1 year 9 months \\
\hline
\end{tabular}

\section{Vocabulary Assessment}

The mean vocabulary score is shown in Column 2 of Table 1. The range of scores was rather narrow (6 to 12), and this may have some bearing on the correlations to be discussed.

\section{Digit-Span Assessment}

Each child was given a score, out of a possible 26. The range was from 7 to 26 . Mean digit sequencing scores are shown in Column 3 of Table 1.

\section{Reading Ability Assessment}

The average of the scores for the three subtests was used in the data analyses; this average is shown in Table 2. The average age of the subjects at the time of the reading testing is also shown in Table 2.

A reading age/chronological age discrepancy score, based on the difference between a child's chronological age at the time of testing and his/her average reading age, was also determined. This was +7.4 months, as shown in Column 3 of Table 2. On average, reading ages were 7 months ahead of chronological age. The range was from 1.9 years behind to 2.9 years ahead.

\section{Multiple Regression Analyses}

The extent to which the vocabulary, digit-span, and contrast-sensitivity scores predicted reading ability 2 years later was determined using a stepwise multiple regression procedure (Hull \& Nie, 1981). On the first step, contrast sensitivity only was entered. The multiple $R$ was 0.27 , $R^{2}$ was 0.07 , and $F(1,121)=9.2$ was significant at the .01 level. Contrast sensitivity, therefore, was a significant predictor of reading ability. Vocabulary was entered on the second step, taking the multiple $R$ to 0.35 and $R^{2}$ to 0.13 . This $[F(2,120)=8.6]$ was also significant at the .01 level. On the third step, digit span was entered. The multiple $R$ was $0.40, R^{2}$ was 0.16 , and $F(3,119)=7.4$ was significant at the .01 level. The final regression equation was

$$
\begin{aligned}
& \text { Predicted Age Difference } \\
& \begin{aligned}
= & 2.82 \text { (Contrast Sensitivity) }+.23 \text { (Vocabulary) } \\
& +.05 \text { (Digit Span) }-6.55
\end{aligned}
\end{aligned}
$$

and the Pearson correlation between predicted age difference and the actual age difference was 0.40 .

To determine whether contrast sensitivity made any unique contribution to the multiple regression equation, we removed contrast sensitivity from the regression equa- 
tion. This resulted in an $R^{2}$ change of -0.099 and an $F$ change of 13.98. This change was significant at the .01 level, thus indicating a unique contribution by contrast sensitivity to the regression equation. Removing vocabulary from the regression equation resulted in an $R^{2}$ change of -0.039 and an $F$ change of 5.46, and removing digit span resulted in an $R^{2}$ change of -0.031 and an $F$ change of 4.43 .

\section{DISCUSSION}

Two major aspects of the data should be commented on. The first concerns the finding that a low-level visual measure is a reasonable predictor of reading ability 2 years after the commencement of reading instruction. Earlier research, discussed in the introduction, tended not to show such a relationship after Grade 1. Furthermore, this relationship has been found in a representative sample of early readers. The data, therefore, do add some strength to the claim that low-level visual deficits may be involved in reading disability. It should be noted that very few of these children had visual-acuity deficits (primarily a measure of the sustained system). This lends support to the speculation made in the introduction that previous studies have failed to find a predictive relationship because they measured functioning of the sustained system.

The second aspect of the data to note is that within the multiple $R$, contrast sensitivity did make a significant and unique contribution. In this respect, the present study contrasts strongly with previous studies in which measures of "visual processing"' have not been entered in the multiple $R$ (Satz \& Friel, 1974). There are two reasons why this may have occurred: The visual mechanisms assessed in the present study are almost certainly different from those assessed in previous studies, and there is firm evidence suggesting that the measures taken here should relate to reading ability.

Previous research from this laboratory, based on at least 150 SRDs, has shown approximately $80 \%$ of them to have a low-level visual deficit. This deficit is primarily in the transient system. There is evidence (Breitmeyer et al., 1981) of some transient-system involvement in the task used in this research. The involvement of the transient system in pattern-contrast-sensitivity tasks is not as great as it is in other tasks that have been used more recently (Martin \& Lovegrove, 1986). The latter tasks, which measure sensitivity to counterphase flickering gratings, have proven to be much more accurate in differentiating SRDs from controls on the basis of visual measures alone. Furthermore, they are regarded as direct measures of transient-system functioning. Thus, it is reasonable that the data reported here show only a small but significant correlation between contrast sensitivity and reading. It would be expected that the recent and more direct measures of transient-system processing would be better predictors of reading ability. This expectation is about to be tested in this laboratory.
On the basis of the data reported here, it can be concluded that differences in low-level visual processing between good and poor readers are present before reading commences. The visual deficits do not, therefore, result from failure to learn to read. What the data do not show is how a transient-system deficit may lead to reading disability. The predictive relationship between contrast sensitivity and reading ability, however, is suggestive of such a relationship and may prove a useful addition to current predictive measures.

\section{REFERENCES}

BaDcock, D. R., \& Lovegrove, W. (1981). The effect of contrast, stimulus duration and spatial frequency on visible persistence in nor$\mathrm{mal}$ and specifically disabled readers. Journal of Experimental Psychology: Human Perception \& Performance, 7, 496-505.

BENTON, A. L. (1962). Dyslexia in relation to form perception and directional sense. In J. Money (Ed.), Reading disability: Progress and research needs in dyslexia. Baltimore: Johns Hopkins Press.

Benton A. L. (1975). Developmental dyslexia: Neurological aspects. In W. J. Friedman (Ed.), Advances in neurology: Vol. 1. Current reviews of higher nervous system dysfunction. New York: Raven Press.

Blakemore, C. \& Campbell, F. W. (1969). On the existence of neurones in the human visual system selectively sensitive to the orientation and size of retinal images. Journal of Physiology (London), 203, 237-260.

BODER, E. (1973). Developmental dyslexia: A diagnostic approach based on three atypical reading patterns. Developmental Medicine \& Child Neurology, 15, 663-687.

Bowling, A., Lovegrove, W., \& Mapperson, B. (1979). The effect of spatial frequency and contrast on visible persistence. Perception, 8, 529-539.

Breitmeyer, B. G. (1975). Simple reaction time as a measure of the temporal response properties of transient and sustained channels. $\mathrm{Vi}$ sion Research, 15, 1411-1412.

BREITMEYER, B. G. (1980). Unmasking visual masking: A look at the "why" behind the veil of "how." Psychological Review, 87, 52-69.

BREITMEYER, B. G. (1983). Sensory masking, persistence, and enhancement in visual exploration and reading. In K. Rayner (Ed.), Eye move ments in reading: Perceptual and language processes. New York: Academic Press.

BREITMEYER, B. G., \& GANZ, L. (1976). Implications of sustained and transient channels for theories of visual pattern masking, saccadic suppression and information processing. Psychological Review, 83, 1-36.

Breitmeyer, B. G., \& Ganz, L. (1977). Temporal studies with flashed gratings: Inferences about human transient and sustained channels. Vision Research, 17, 861-865.

BReitMeyer, B. G., LeVi, D., \& HaRWERTH, R. (1981). Flicker masking in spatial vision. Vision Research, 21, 1377-1385.

Burbeck, C., \& Kelly, D. (1981). Criterion-free pattern and flicker thresholds. Journal of the Optical Society of America, 71, 1343-1350.

CAMPBELl, F. W. (1974). The transmission of spatial information through the visual system. In F. O. Schmidt \& F. S. Worden (Eds.), The neurosciences third study program. Cambridge, MA: MIT Press.

Clark, C. R., Bruinink, R. H., \& Glaman, G. V. (1978). Kindergarten predictors of three aspects of reading achievement. Perceptual \& Motor Skills, 46, 411-419.

Derrington, A. M., \& Henning, B. (1981). Pattem discrimination with flickering stimuli. Vision Research, 21, 597-602.

Doenring, D. G. , \& Hoshko, I. M. (1977). Classification of reading problems by the Q-technique of factor analysis. Cortex, 13, 281-294.

GreEN, M. (1984). Masking by light and the sustained-transient dichotomy. Perception \& Psychophysics, 35, 519-535.

HuLL, C. H., \& NIE, N. H. (1981). SPSS update 7-9: New procedures and facilities for releases 7-9. New York: McGraw-Hill. 
KeESEY, V. T. (1972). Flicker and pattern detection: A comparison of thresholds. Jourmal of the Optical Society of America, 62, 446-448.

KuLkowski, J. J. \& TolnuRst, D. J. (1973). Psychophysical evidence for sustained and transient detectors in human vision. Joumal of Physiology, 232, 149-162.

LEGGE, G. E. (1978). Sustained and transient mechanisms in human vision: Temporal and spatial properties. Vision Research, 18, 69-81.

LENNIE, P. (1980). Parallel visual pathways: A review. Vision Research, 20, 561-594.

Lovegrove, W. J., Bowling, A., BADCock, D., \& BLACKWOOD, M. (1980). Specific reading disability: Differences in contrast sensitivity as a function of spatial frequency. Science, 210, 439-440.

Lovegrove, W., Heddle, M., \& Slaghuis, W. (1980). Reading disability: Spatial frequency specific deficits in visual information store. Neuropsychologia, 18, 111-115.

Lovegrove, W., Martin, F., Bowling, A., Blackwood, M., BadCOCK, D., PAXTON, S. (1982). Contrast sensitivity functions and specific reading disability. Neuropsychologia, 20, 309-315.

Lovegrove, W., Martin, F., Hart, J., s Cuthbert, A (1986). Spatial vision in normal and specifically disabled readers. Manuscript in preparation.

Lovegrove, W., Martin, F., Slaghuis, W. (1986). A theoretical and experimental case for a visual deficit in specific reading disability. Cognitive Neuropsychology, 3, 225-267.

Manis, F. R., Morrison, F. J. (1982). Processing of identity and position information in normal and disabled readers. Journal of Experimental Child Psychology, 33, 74-86.

Martin, F., \& Lovegrove, W. (1984). The effects of field size and luminance on contrast sensitivity differences between specifically reading disabled and normal children. Neuropsychologia, 22, 73-77.

MarTIN, F., L LOVEGRove, W. (in press). Flicker sensitivity in specific reading disability. Perception.

MAtTs, S., French, J. H., \& RAPIN, I. (1975). Dyslexia in children and young adults: Three independent neurophysiological syndromes. Developmental Medicine \& Child Neurology, 17, 150-163.

MCNiNCH, G. (1974). Awareness of aural and visual word boundaries within a sample of first graders. Perceptual \& Motor Skills, 38, 1127-1134.

MeYer, G. E., \& Maguire, W. M. (1977). Spatial frequency and the mediation of short-term visual storage. Science, 198, 524-525.

NeALE, M. B. (1966). The Neale analysis of reading ability. London: Macmillan.
PANTLE, A. J. (1983). Temporal determinants of spatial sine-wave masking. Vision Research, 23, 749-765.

REGAN, D., \& NeIMA, D. (1984). Balance between pattern and flicker sensitivities in the visual fields of ophthalmological patients. British Journal of Ophthalmology, 68, 310-315.

Satz, P., \& Friel, J. (1974). Predictive antecedents of specific reading disability: A preliminary two-year follow-up. Journal of Learning Disabilities, 7, 437-444.

SATz, P., \& MoRRIS, R. (1981). Learning disability sub-types: A review. In F. J. Pirozzolo \& M. C. Whittrock (Eds.), Neuropsychological and cognitive processes in reading. New York: Academic Press.

Staghuis, W., LoVEgrove, W. J. (1984). Flicker masking of spatial frequency-dependent visible persistence and specific reading disability. Perception, 13, 527-534.

Slaghuis, W., \& LoVegrove, W. J. (1985). Spatial-frequency mediated visible persistence and specific reading disability. Brain \& Cognition, 4, 219-246.

Tasmanian early assessment programme (1977). Hobart, Tasmania, Australia: State Education Department.

Van Nes, F. L., Koenderick, J. J., Nas, H, Bouman, M. A. (1967). Spatiotemporal modulation transfer in the human eye. Journal of the Optical Society of America, 57, 1082-1088.

Vassilev, A., \& Mitov, D. (1976). Perception time and spatial frequency. Vision Research, 16, 89-92.

Vellutino, F. R. (1979). Dyslexia: Theory and research. London: MIT Press.

Warren, D. H., Anooshian, L. J., \& Widawski, M. H. (1975). Measures of visual-auditory integration and their relations to reading achievement in early grades. Perceptual \& Motor Skills, 41, 615-630.

Warren, D. H., WidaWSKI, M. H., \& ANoOShian, L. J. (1976). Prediction of first grade reading achievement from performance on perceptual tests in kindergarten. Perceptual \& Motor Skills, 42, 571.

Watson, A. B., \& Nachmias, J. (1977). Patterns of temporal interaction in the detection of gratings. Vision Research, 17, 893-902.

Williams, J. D., BREKKE, B.W. (1977). Effect of a visual motor program on school achievement: A longitudinal study. Percepsual \& Motor Skills, 45, 786.

(Manuscript received December 19, 1985; revision accepted for publication September 25, 1986.) 